\title{
Thought Leader Dennis Jaffe: What the Best Family Businesses Get Right
}

\author{
Kimberly Eddleston (Northeastern University)
}

KEYWORDS: Management, Family Business.

Dennis Jaffe(https://dennisjaffe.com) is a thought leader on family businesses -- an organizational consultant and clinical psychologist, and one of the architects of the emerging field of family enterprise consulting. He is a family business fellow at the Cornell Johnson College of Business, Senior Research Fellow at BanyanGlobal Family Business Advisors, and the author of several books.

In this interview with family business Editor Kimberly Eddleston, Jaffe shares the insights gained from his research into family firms from around the world that have lasted 100 years or more. This research informed his latest book, "Borrowed From Your Grandchildren: The Evolution of 100-Year Family Enterprises."

The key takeaways? Balance the needs to be professional and also innovative. Involve the older and younger generations and outside advisors. Engage with the younger generation frequently and encourage them to do more. And get the entire family aligned on values. 